\title{
Hybrid Method and Face to Face Method in Teaching Mathematics: Effects on Students' Performance
}

\author{
Luisito Lolong Lacatan, Member, IACSIT
}

\begin{abstract}
The study is a quasi-experimental research which determines the success of hybrid method of teaching to an e-community of learners in cyberspace over the face to face method of teaching and tries to compare the academic performance of the students. Two groups of students are chosen, a control group and an experimental group. The traditional method of teaching is used in the control group and the hybrid method to an e-community of students is implemented in the experimental group. After the groups have been selected, an experimental variable is introduced to the experimental group only, leaving the control group as it was. After the experimental variable has been introduced, the researcher measured both groups on the dependent variable.

With the creation of e-community in the cyberspace, student's capacity is limited to the following: to upload, to read or download. While, the teachers can perform the read, delete, edit capacity in the system.

The system (e-community/e-group) is available $24 / 7$ in the internet so the students have unlimited access time to learning and they can do it anywhere, anytime.

It's vitally important that teachers should keep/stay in touch online with their students as much as possible. This is to make their presence felt and to motivate student participation in the e-community. Teachers should set their limits clear from the outset. They should inform students to allow them reasonable number of hours for an online response to queries.
\end{abstract}

Index Terms-E-learning, distance education

\section{INTRODUCTION}

Hybridity is a mechanism in which two dissimilar parts produce the same function or result. In hybrid method of teaching, face-to-face (F2F) classroom instruction is blended with Web based learning, combining dynamically both technology and human instruction to promote student learning outcomes. The goal of hybrid method is to join the best aspects of in-class teaching with the best features of online learning. The Web is used in place of some class meetings. In this methodology of teaching, significant portions of learning activities is moved online, fifty percent $(50 \%)$ or more of the course is cyber-based. Students have 24/7 (24 hours, 7 days a week) access to course materials [1].

In a hybrid course, some of the course activities accessing of lecture materials, information transfer, and announcement of deadlines, exchange of ideas, submission of requirements and other tasks are done online. Which is why, there is a need for building an electronic community

Manuscript received September 12, 2012; revised December 29, 2012.

Luisito Lolong Lacatan is with Computer Engineering Department College of Engineering, Adamson University-Manila Philippines (e-mail: louie1428@yahoo.com). (e-community) of students in the Internet. In some cases, a Course Management System is used but it can also be accomplished via something as simple as building an electronic group such as yahoo groups [2].

Successful hybridity requires bringing two dissimilar parts together so that they work in concert and produce a third result. In the case of successful hybrid courses, there are two dissimilar methods of teaching that must come together and produce a final result: online and face-to-face methods resulting to an improved student learning outcomes [3].

The present study aims to determine the success of hybrid method of teaching and compare the academic performance of the students. The researcher implemented hybrid method of instruction and form an e-community group of students. The Internet is utilized to deliver course materials to the students.

\section{A. Statement of the Problem}

This study used quasi-experimental to address the following questions regarding the implementation of hybrid method of teaching to an e-community of learners as tested against the face to face method of teaching.

1) Do the e-community of students taught by hybrid method performed better than those in the face-to-face method of teaching?

2) Is there a significant difference in the academic performance of the students taught by hybrid and students taught by face-to-face in the course Engineering Electromagnetic?

\section{B. Assumptions}

This study is built on the following assumptions:

1) That both group of students, the experimental and the control group, are comparable based on a chosen controlled variable, in this case, intelligence.

2) The grade of the students is a fair indices of their academic performance.

3) The examination used in this study is a valid tool to measure students' learning.

\section{Scope and Delimitation}

This research is conducted during the school year 2007-2008 in the campus of the Adamson University, Manila. The principal respondents are the students of College of Engineering enrolled in the course Engineering Electromagnetic.

The study is a quasi-experimental research which determines the academic performance of the students. Two groups of students are chosen, a control group and an experimental group. The traditional method of teaching is used in the control group and the hybrid method to an 
e-community of students is implemented in the experimental group. After the groups have been selected, an experimental variable is introduced to the experimental group only, leaving the control group as it was. After the experimental variable has been introduced, the researcher measured both groups on the dependent variable.

Likewise, numeration and comparative analysis is employed in order to compare the significant differences that exist between the performances of the two groups of respondents.

With the creation of an e-community in the cyberspace, student's capacity is limited to the following: to upload, to read or download. While, the teachers can perform the read, delete, edit capacity in the system.

The system (e-community/e-group) is available 24/7 in the internet so the students have unlimited access time to learning and they can do it anywhere, anytime.

It's vitally important that teachers should keep/stay in touch online with their students as much as possible. This is to make their presence felt and to motivate student participation in the e-community. Teachers should set their limits clear from the outset. They should inform students to allow them reasonable number of hours for an online response to queries.

\section{RESEARCH DESIGN}

The study is a quasi-experimental research. The researcher performed an experiment to determine whether the independent variable affects the dependent variable.

The quasi-experimental method is used to determine the academic performance of the students. Two groups of respondents identical in composition are chosen, a control group and an experimental group. The traditional method of teaching is used in the control group and the hybrid method of teaching is implemented in the experimental group. Matching is used to select the experimental group. The selection is done by using a list of variables, in this case the grades in Phys 2, on which the two groups of respondents was similar. After the groups have been selected, an experimental variable is introduced to the experimental group only, leaving the control group as it was. After the experimental variable has been introduced, the researcher measured both groups on the dependent variable.

The academic performance of the students using the hybrid method of teaching in the experimental group is gathered.

\section{A. Population and Sampling Technique}

The subjects of the study were the students of Computer Engineering of Adamson University enrolled in the course Engineering Electromagnetic during the first semester of 2007-2008.

From the two sections in Engineering Electromagnetic, only twenty-one (21) students from each section are used as respondents of the study.

Two comparable sections in Engineering Electromagnetic are chosen as subjects. One section is assigned as the control group, while the other section as the experimental group. These sections are designated on the bases of the following:

both sections are of the same course both sections are enrolled in the same subject

both sections are handled by the same teacher

Out of forty (40) students in the experimental group only twenty-one (21) students paired with twenty-one (21) students in the control group taking into account the following criteria of pairing/matching: same mental ability, same course, same subject, and same teacher. The grades of the students in Physics 2 were considered to determine the comparability of the two groups in mental ability.

\section{B. Data Gathering Procedure}

For this research, the researcher asked the permission of the Department Chairperson of Computer Engineering to allow the researcher to conduct the experimental research.

The experimental group was subjected to Hybrid method and the control group to the traditional face-to-face classroom method of instruction. The experiment was conducted from July - September, 2007. Both classes are handled by the researcher at their usual regular schedule: 9:00 - 10:30 for the control group and 12:30 - 2:00 for the experimental group. While conducting the experiment, the teacher's role was to give information through web-based course ware, sent prepared lecture notes, exercises, assignments, announcements of quizzes, deadline of submission, to the students through their e-mail addresses, and give lectures to call attention to main ideas, and reviewed salient points at the end.

Hybrid Method is a methodology of teaching that combines the face-to-face method and the online method. Fifty percent or more of the classroom activities are moved online. Lecture materials, information transfer, and announcement of deadlines, exchange of ideas, submission of requirements and other tasks are done online. Quizzes and examinations are done in the classroom.

After the treatment, the two groups of respondents were given the midterm examination and, quizzes included, to determine their academic performance. To compute for the student's academic performance, the following steps are done:

1) Add all the scores got by the students from their activities (quizzes, assignment and midterm exam).

2) Divide the total scores by the total number of items and multiply by 60 (60\% is the passing score) and then add $40(40 \%$ is the base line score).

3) Convert the percentage grades to grade point equivalent using the following conversion.

The converted results are as follows:

$$
\begin{aligned}
& 1.00=99-100 ; 1.10=97-98 ; 1.20=95-96 ; \\
& 1.30=93-94 ; 1.4=91-92 ; 1.5-2.00=90-85 \text {; } \\
& 2.10-2.50=84-80 ; 2.60-3.00=79-75 \\
& \text { Grade Verbal Interpretation } \\
& 1.00-1.20 \quad \text { Outstanding } \\
& 1.30-1.70 \quad \text { Very Satisfactory } \\
& 1.80-2.50 \quad \text { Satisfactory } \\
& 2.60-3.00 \quad \text { Fair } \\
& 4.00-5.00 \quad \text { Poor }
\end{aligned}
$$

\section{INSTRUMENTATION AND INTERPRETATION}

To determine the academic performance of the students, 
quizzes and assignments were given and the midterm test is administered. The test is based on the lessons given. The coverage of the lessons was the topics on Vector Analysis, Coulomb's Law and Electric Field Intensity, Volume Charge Distribution, Line Charge, Sheet Charge and Streamlines and Sketches.

To determine the academic performance of the students in the experimental group on the use of hybrid method, a survey-questionnaire is given.

\section{PRESENTATION, ANALYSIS AND INTERPRETATION OF DATA}

This chapter deals with the presentation, analysis and interpretation of data gathered, following the sequence of the questions presented.

\section{A. Academic Performance of e-Community of Students Taught by Hybrid Method}

TABLE I: ACADEMIC PERFORMANCE OF E-COMMUNITY OF STUDENTS TAUGHT BY HYBRID METHOD (EXPERIMENTAL GROUP)

\begin{tabular}{|c|c|c|}
\hline Grade & Frequency & Percentage \\
\hline $2.20-2.39$ & 11 & 52 \\
\hline $2.40-2.59$ & 9 & 43 \\
\hline $2.60-2.79$ & 1 & 5 \\
\hline $2.80-3.00$ & 0 & 0 \\
\hline TOTAL & 21 & 100 \\
\hline \multicolumn{3}{|c|}{ MEAN GRADE $=\mathbf{2 . 3 6}$} \\
\hline
\end{tabular}

Table I shows that from a total of twenty-one (21) respondents, more than half which is eleven (11) or 52\% got grades of $2.20-2.39$, followed by nine (9) or $43 \%$ belonging to $2.40-2.59$ grade bracket. It may be noted that only one (1) or $5 \%$ received grade of $2.60-2.79$ and no one got grade from $2.80-3.00$. The mean academic performance of the students taught by hybrid is 2.36 .

This academic performance is a result of all classroom and online activities done by the students. Activities includes downloading of lecture notes, assignment and seatworks posted by the teacher online, quizzes and exams given in the room, and classroom/online participation of the students.

\section{B. Academic Performance of Students Taught by Face-to-Face}

TABLE II: ACADEMIC PERFORMANCE OF STUDENTS TAUGHT BY FACE-TO-FACE (CONTROL GROUP)

\begin{tabular}{|c|c|c|}
\hline Grade & Frequency & Percentage \\
\hline $2.20-2.39$ & 1 & 5 \\
\hline $2.40-2.59$ & 4 & 19 \\
\hline $2.60-2.79$ & 1 & 5 \\
\hline $2.80-3.00$ & 15 & 71 \\
\hline TOTAL & 21 & 100 \\
\hline \multicolumn{3}{|c|}{ MEAN GRADE $=\mathbf{2 . 7 5}$} \\
\hline
\end{tabular}

Table II revealed that majority of the students got grades ranging from $2.80-3.00$. The computed mean grade showed 2.75 .

It can be inferred that compared to the face-to-face method, more students performed well in the hybrid method as evidenced by the percentage passing rate.

Students taught by the hybrid method were able to participate actively in the duration of the course. They were excited about the new method of learning in Engineering Electromagnetic, which is, receiving hybrid lessons in their e-mail addresses. The course was made personalized and "technologized".

TABLE III: SUMMARY OF PERFORMANCE OF STUDENTS TAUGHT BY HYBRID METHOD AND FACE-TO-FACE METHOD

\begin{tabular}{|c|c|c|}
\hline Student No. & Hybrid Method & Face-to-face \\
\hline 1 & 2.20 & 2.90 \\
\hline 2 & 2.50 & 2.70 \\
\hline 3 & 2.40 & 3.00 \\
\hline 4 & 2.20 & 2.70 \\
\hline 5 & 2.20 & 2.90 \\
\hline 6 & 2.30 & 2.80 \\
\hline 7 & 2.20 & 2.80 \\
\hline 8 & 2.30 & 2.90 \\
\hline 9 & 2.40 & 3.00 \\
\hline 10 & 2.20 & 2.80 \\
\hline 11 & 2.60 & 3.00 \\
\hline 12 & 2.20 & 2.50 \\
\hline 13 & 2.50 & 3.00 \\
\hline 14 & 2.30 & 2.40 \\
\hline 15 & 2.60 & 2.60 \\
\hline 16 & 2.20 & 2.80 \\
\hline 17 & 2.30 & 2.30 \\
\hline 18 & 2.40 & 2.90 \\
\hline 19 & 2.50 & 2.40 \\
\hline 20 & 2.50 & 2.50 \\
\hline 21 & 2.50 & 2.90 \\
\hline Mean Grade & 2.36 & 2.75 \\
\hline
\end{tabular}

Table III shows the summary of performance of the students taught by hybrid method is 2.36 , interpreted as Very Satisfactory, and the mean performance of the students taught by face-to-face is 2.75 interpreted as Fair.

The finding of this study is the same with the findings of Curtis \& Swenson (2003) where they explored the potential within hybrid courses for increasing student learning by considering the benefits of hybrid courses of matching the pedagogies of face-to-face and online to their needs and the desired learning outcomes [4].

\section{SUMmARY OF FINDINGS}

Based on the analysis and interpretation of data the following findings were revealed:

Academic performance of e-community of students taught by:

\section{A. Hybrid Method}

The results showed that eleven (11) got grades of $2.20-$ 2.39 , followed by nine belonging to $2.40-2.59$ grade bracket. It may be noted that only one received grade of $2.60-2.79$ and no one got grade from $2.80-3.00$. The mean academic performance of the students taught by hybrid is 2.36 interpreted as Good.

\section{B. Face-to-Face Method}

Findings revealed that majority of the students got grades ranging from $2.80-3.00$. The computed overall mean grade showed 2.75 interpreted as Fair.

The Internet plays an important part in the hybrid method of instruction, performing not only as a repository of information, but its conduit as well. A Computer World special report written by Ronald James Panis entitled 
"Internet Becoming a Popular Tool for Remote Education", mentioned that the NET has become a tool for learning and a pool of knowledge as evidenced by the rising popularity of online education [5].

\section{REFERENCES}

[1] P. Sands, Strategies for Connecting Online and Face-to-Face Instruction in Hybrid Courses, vol. 8, no. 6, March 20, 2002.

[2] S. K. Cho and Z. L. Berge, "Overcoming Barriers to Distance Training and Education. Education at a Distance," USDLA Journal, vol. 16, no. 1, 2002.

[3] C. Bazerman and D. R. Russell, Ed., "Landmark Essays on Writing Across the Curriculum," Landmark Essays 6. Davis, CA: Hermagoras Press, 1994

[4] L. Curtis and P. Swenson, "Hybrid Courses Plus: Blending F2F, online and handheld computer for effective learning," in C. Crawford et al. Eds., in Proc. of Society for Information Technoloy and Teacher
Education International Conference 2003, Chesapeake, VA: AACE pp. 520-523, 2003.

[5] Panis and R. James, "Internet Becoming Popular Tool for Remote Education," Computer World, vol. 12, no. 14, pp. 4, June 2, 2003.

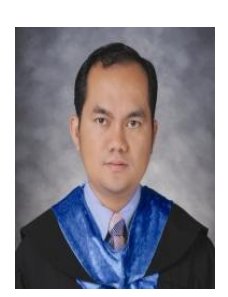

Luisito Lolong Lacatan is a permanent faculty member of Adamson University, Philippines in College of Engineering Computer Engineering Department. He is a graduate of BSc in Computer Engineering (BSc. CpE), Master of Engineering in Computer Engineering (MEng-CpE) and Doctor of Philosophy - Mathematics (PhD-Mathematics). He is a Member of Regional Quality Assessment Team (RQAT) of the Commission on Higher Education (CHED), Philippines for Engineering Education. He is also a Senior Member of International Association of Computer Science and IT (Singapore). He was invited as a Conference Paper Reviewer of International Conferences. 